\title{
Noveleiros on-line: como os fãs podem transformar uma novela em cult
}

\section{Clarice Greco ${ }^{1}$}

Recibido: 2017-01-19

Enviado a pares: 2017-02-14
Aprobado por pares: 2017-03-13

Aceptado: 2017-04-04

DOI: 10.5294/pacla.2017.20.4.3

Para citar este artículo / to reference this article / para citar este artigo

Greco, C. (2017). Noveleiros on-line: como os fãs podem transformar uma novela em cult. Palabra Clave 20(4), 884-916. D0I: 10.5294/pacla.2017.20.4.3

\section{Resumo}

Nas conversas do dia a dia e nas redes sociais, é possível nos depararmos com o termo cult em referência a pessoas, lugares, filmes ou programas televisivos. A proposta deste artigo é apresentar conceituações acerca do conceito de "TV cult" aplicado às ficções televisivas brasileiras, especialmente às telenovelas. A primeira parte concentra-se no diálogo teórico entre autores que discutem o conceito de TV cult (Pearson, 2010; Hills, 2010) e apontam a relação da expressão ao conteúdo inovador ou crítico de uma narrativa, ao seu apelo nostálgico ou, principalmente, ao engajamento de fãs. Em seguida, descreve-se a pesquisa empírica realizada em três etapas: 1) análise de tweets a fim de traçar um paralelo entre as conceituações teóricas e o uso do termo pelos telespectadores; 2) questionário aplicado nas redes on-line que apontou as telenovelas consideradas cult pelos telespectadores e 3) grupo focal com discussão das razões para que tais novelas tenham sido mencionadas. A partir dessas orientações, o artigo destaca o engajamento dos fãs em uma das produções mais citadas no questionário:

1 orcid.org/0000-0002-2603-6808. Universidade Paulista (Unip). Brasil. claricegreco@usp.br 
Avenida Brasil, por tratar-se de uma produção recente que deixou visível a relação entre a noção de cult e a manifestação dos fãs on-line. Como resultado, o artigo contribui para a conceituação teórica do cult, estabelece um diálogo entre as teorias internacionais e o contexto brasileiro e, a partir da voz dos telespectadores, mostra como os fãs podem transformar uma telenovela em uma obra cult.

\section{Palavras-chave}

TV cult; fãs; telenovela; Avenida Brasil (Fonte: Tesauro da Unesco). 


\section{Noveleros en línea: cómo los fans pueden transformar una telenovela en culto}

\section{Resumen}

En las conversaciones del día a día en las redes sociales, es posible que no deparemos con el término culto con referencia a personas, lugares, películas o programas de televisión. La propuesta de este artículo es presentar conceptos sobre "televisión de culto" aplicado a las ficciones brasileiras de televisión, especialmente a las telenovelas. La primera parte se enfoca en el diálogo teórico entre autores que discuten el concepto de televisión de culto (Pearson, 2010; Hills, 2010) y señalan la relación de la expresión al contenido innovador o crítico de una narrativa, a su función nostálgica o, principalmente, al comprometimiento de los fans. Luego, se describe la investigación empírica realizada en tres etapas: 1) análisis de tweets con el fin de trazar un paralelo entre los conceptos teóricos y el uso del término por los telespectadores; 2) cuestionario aplicado en las redes en línea que señaló las telenovelas consideradas culto por los telespectadores; y 3 ) grupo focal con discusión de las razones por las que tales telenovelas hayan sido mencionadas. A partir de esas orientaciones, el artículo destaca el compromiso de los fans en una de las producciones más mencionadas en el cuestionario: Avenida Brasil, por tratarse de una producción reciente que evidencio la relación entre la noción de culto y la manifestación de los fans en línea. Como resultado, el artículo contribuye a la conceptuación teórica del culto, establece un diálogo entre las teorías internacionales y el contexto brasilero y, a partir de la voz de los telespectadores, muestra cómo los fans pueden transformar una telenovela en una obra de culto.

\section{Palabras clave}

Televisión de culto; fans; telenovela; Avenida Brasil (Fuente: Tesauro de la Unesco). 


\section{Online Soap-Opera Buffs: How Fans Can Turn a Soap Opera into a Cult}

\section{Abstract}

In everyday conversation and in the social networks, we may come across the term cult in reference to people, places, movies or television programs. In this paper, we propose a few conceptualizations about the notion of cult $T V$, applied to Brazilian television fiction, and particularly soap operas. The first section focuses on the theoretical dialogue between authors who discuss the concept of cult TV (Pearson, 2010; Hills, 2010) and who point out the relationship between the expression and the innovative or critical content of a narrative, its nostalgic appeal or, mainly, to fan engagement. Then, we describe the empirical research carried out in three stages: 1) analysis of tweets in order to draw a parallel between the theoretical conceptualizations and the use of the term by the viewers; 2 ) questionnaire administered in online networks that pointed out which soap operas were considered as cult by viewers; and 3) focal group discussing the reasons why those soap operas were mentioned. Based on these guidelines, the paper highlights fans' investment in one of the most cited productions in the questionnaire, Avenida Brasil, a recent production that made visible the link between the concept of cult and fans' manifestations online. As a result, the paper contributes to the theoretical conceptualization of cult, opens a dialogue between international theories and the Brazilian context and shows, from the point of view of viewers, how fans can turn a soap opera into a cult.

\section{Keywords}

TV cult; fans; soap opera; Avenida Brasil (Source: Unesco Thesaurus). 


\section{Introdução}

No dia a dia, é comum nos depararmos com termos ou expressões utilizados no senso comum, em referência a diversos aspectos da vida cultural e cotidiana. Um desses termos é o cult. Considerando-se a telenovela como um importante produto cultural brasileiro e as recentes discussões teóricas internacionais acerca do termo aplicado à TV, surge aqui o interesse em investigar o que seria, para os telespectadores, uma "telenovela cult".

De acordo com estudos iniciais (Eco, 1985; Pearson, 2010; Hills, 2010), a expressão TV cult se refere ao caráter específico de certas produções ou do comportamento do público quando os telespectadores se tornam fãs. O caráter cult seria, em resumo, relativo a: 1) programas ou filmes que angariam fãs devotos e fiéis; 2) obras com alto valor ritual ou nostálgico e/ou 3) produções de conteúdo inovador. Normalmente, também, associado a obras não populares.

Como esses estudos se concentram no hemisfério norte, o termo acaba por ser associado especialmente a programas norte-americanos e ingleses, que provocam fenômenos de audiência bastante distintos do que se vê no Brasil. Isso evidencia a necessidade de pensar o termo no contexto nacional e latino-americano a fim de identificar se as telenovelas, principal produto televisivo do Brasil, podem ser chamadas de cult, e qual o significado dessa expressão no país.

Acontece que as telenovelas e as séries sempre apresentaram fortes traços do melodrama e, por serem populares, distanciam-se das definições mais utilizadas no cenário internacional. Enquanto alguns autores se mostravam descrentes com a relação entre cult e popular, surgem estudiosos que defendem a associação e criticam a distinção entre os conceitos, como Jancovich e Hunt (2004) e Sandvoss (2013). Principalmente, pelo ponto de vista do engajamento dos fãs de telenovela, chamados carinhosamente de noveleiros, nas redes sociais.

Assim, proponho aqui pensar na aplicação do conceito às populares telenovelas. A partir do diálogo teórico entre autores que discutem o conceito 
de TV cult (Pearson, 2010; Hills, 2010), apresento neste artigo, decorrente de minha pesquisa de doutorado recém-concluída, a pesquisa empírica que envolveu análise em três etapas: 1) de tweets, a fim de compreender os usos do termo pelos telespectadores; 2) das respostas a um questionário que apontaram as telenovelas consideradas cult pelos telespectadores e 3) de dois grupos focais que debateram as razões para que tais novelas tenham sido mencionadas. A partir dessas orientações, o artigo destaca o engajamento dos fãs em uma das produções mais citadas no questionário: Avenida Brasil, por tratar-se de uma produção que deixou visível a relação entre a noção de cult e a manifestação da audiência on-line, além de mostrar como os fãs podem transformar uma telenovela em uma obra cult.

\section{0 que é um programa cult?}

O termo cult no contexto televisivo é frequentemente utilizado pelo público, mas a reflexão teórica sobre seu significado é escassa e relativamente recente. Como consequência, a bibliografia dos estudos de TV e cinema cult aborda o assunto de forma diversa e discordante. A ausência de um acordo básico em relação a quais textos ou obras particulares podem ser descritos com exatidão como cult causam confusão sobre seu significado (Grant, 2000). $\mathrm{O}$ termo é aplicado às vezes em referência à produção, outras à audiência ou, ainda, à descrição de um gênero narrativo (nesse caso, associado a vários gêneros, como terror, ficção científica ou fantasia).

As primeiras acepções de cult ressaltavam um caráter segregador. $\mathrm{O}$ status era associado àquilo que se distingue do popular, do "normal", dos padrões vistos no cinema ou na TV. A audiência dos programas de TV cult se caracterizava, segundo Pearson (2010), por preferir programas distintos dos campeões da televisão aberta e por defender seus programas favoritos. Na mesma linha, Hills (2010) diz haver certo consenso sobre o que cult não é: não é vastamente popular, não é culturalmente onipresente, não é lugar-comum ou senso comum. Por outro lado, o próprio autor discorda da rigidez dessa premissa e arrisca ensaios que relacionam o cult ao popular.

Segundo Pearson (2010), o termo cult é livremente aplicado a qualquer programa televisivo que seja considerado fora do padrão ou que seja 
ousado, que abarque um nicho específico da audiência, que tenha apelo nostálgico, que seja considerado emblemático de alguma subcultura particular ou que seja considerado "descolado".

Em ensaio sobre Casablanca, Eco (1985) sugeriu que um texto cult deveria cumprir três critérios básicos: 1) ser apreciado por ao menos um pequeno grupo de fãs; 2) prover um mundo completo e mobiliado para que os personagens e os cenários possam ser citados pelos fãs como se estes neles habitassem, e 3) ser composto de segmentos narrativos que possam ser lidos, vivenciados e recordados, independentes do todo.

Um quarto elemento dos filmes cult é ressaltado por Eco (1985) não como critério a ser cumprido, mas também como característica presente em filmes que já nascem com a proposta de se tornarem cult: as referências ou menções a outras obras embutidas na narrativa. Quando o conhecimento completo da narrativa requer um grau de exigência do espectador, na visão de Eco, ela redefine um nicho, no qual quem assiste deve possuir competências de um verdadeiro fã. O chamado cultista (cultist) deveria dominar detalhes da trama, dos bastidores, dos atores e saber citar frases do filme. Também as ficções televisivas, quando referidas como cult, seriam dotadas das mesmas características presentes no cinema, do qual o termo foi herdado. Nesse critério, a telenovela também encontraria suporte uma vez que os bordões de personagens são parte integrante de conversas cotidianas, inclusive nos grupos focais que descreverei adiante. Os bordões de telenovela são representativos da inserção da telenovela no cotidiano pela linguagem coloquial. Além de indicarem simpatia do público, eles constituem elementos de visibilidade de práticas de audiência (Depexe, 2015).

Quando o tema parece complexo o suficiente, aparece o cult como gênero narrativo. Alguns pesquisadores associam normalmente os textos cult aos gêneros fantástico, horror ou ficção científica. Para Gwenllian-Jones e Pearson (2004), essa ligação acontece porque, em narrativas realistas, a "elasticidade" e a licença poética, apesar de existirem, demandam veracidade e coerência às quais as narrativas fantásticas não precisam obedecer, tal como progressão 
temporal cronológica. As autoras alegam que as narrativas fantásticas permitem maior número de histórias paralelas, ou múltiplas histórias em segundo plano, para o telespectador explorar. Apesar de a telenovela brasileira, no geral, ter como marca o realismo e a verossimilhança, algumas das telenovelas citadas como cult pelos telespectadores apresentam elementos de narrativa fantástica, como Saramandaia e $\mathrm{O}$ Bem-amado. Além disso, o formato conta com vasto número de personagens e núcleos de diversos gêneros (não é raro que, na mesma trama, a comédia conviva com o drama e o suspense), o que a diferencia das telenovelas mexicanas ou das soap operas inglesas e norte-americanas.

Sandvoss (2013), por sua vez, sugere que o cult é definido mais pela audiência do que pela produção ou pelo gênero, concordando com Jancovich e Hunt (2004), que apontam o problema na definição desse termo como decorrente não da existência de características compartilhadas pelos programas em si, mas pelos modos como eles são apropriados por audiências e grupos específicos. Le Guern (2004) adere à linha de pensamento sociológica, na qual o contexto e a audiência definem mais o cult do que o texto. Contudo, aponta que o cult pode ser composto por uma gama heterogênea de audiências, como nicho segmentado e especializado, audiência geracional, cultura jovem ou mesmo pelo interesse em massa de uma audiência que adquire aspecto de fenômeno social. Pearson (2010) compartilha da mesma opinião, alegando que a característica comum entre as produções consideradas cult não estaria só nos textos, mas também nos espectadores que oferecem um alto nível de devoção. Elas provocam uma atração que não é apenas fruto da busca por entretenimento, mas abarca também um envolvimento físico e emocional.

Com isso, por manterem foco na audiência, as análises passaram a admitir o "cult popular", que mantém algumas características textuais e cujos telespectadores apresentam traços de comportamento e afeto que se assemelham aos nichos de audiência cult, porém de forma mais ampla. Seria nesse espaço de avanços teóricos que a popular telenovela passaria a ser admitida como obra cult. 


\section{Avanços teóricos e a aceitação do cult popular}

Conforme exposto anteriormente, as definições iniciais do cult postulavam um público fiel em comunidades formais, com hierarquia entre os "verdadeiros fãs”, e afastada do chamado mainstream. Abbott (2010) desconstrói essa dicotomia ao explicar que, inicialmente, a TV cult era vista como algo da competência de adolescentes socialmente desajeitados, nerds, mas que agora se tornou campo para diferentes tipos de público. Não apenas o conceito de nerd se alargou, como a noção de cult acolhe também uma gama mais diversificada de produções, que hoje em dia vai além das séries de horror e ficção científica, ao abrangerem comédias e dramas.

Lavery (2010), na introdução do livro The Essential Cult TV Reader, organizado pelo próprio, conta que sugeriu uma lista de ficções televisivas a serem consideradas para análise, a qual incluía Grey's Anatomy (2005-). Segundo ele, houve objeção por parte de alguns autores colaboradores, afinal, "como um programa melodramático de entretenimento poderia ser considerado cult e merecer cobertura num livro como esse?". Lavery (2010) defendeu sua posição com o argumento de que a série estava em conformidade com o teste básico de cult estabelecido por Hills (2010), por atrair uma audiência de fãs duradora, apaixonada e socialmente organizada.

Grey's Anatomy não entrou na lista final, mas o caso dá margem para a discussão sobre a validade dessa dicotomia. Para Lavery (2010), essa problemática se tornou pertinente no debate sobre mídia cult no século XXI. Os limites entre o cult e o popular fizeram-se turvos e este é, para Williams (2013), um dos principais progressos na teorização do conceito. A autora questiona a preexistente noção de cult como antipopular, fora dos supostos parâmetros de cultura e entretenimento. Hills (2010) também aponta a possibilidade de existência de um cult popular, em divergência daqueles que o colocam em oposição ao mainstream.

Alguns autores, como Hills (2002), sugeriram, no início do século, não ser possível uma soap opera cult. Oito anos depois, foram incluídas por Lavery (2010) duas soap operas na lista de programas consagrados cult por estudiosos do assunto. O próprio Hills, em entrevista recente (2015), dis- 
se ter repensado a premissa e admitiu a possibilidade de soap operas serem cult. Isso significa que os estudos têm se movimentado, e os exemplos podem ilustrar a grande variedade de significados que, ao fim, atestam nada mais do que a falta de coesão entre os critérios. Mas configuram-se como tentativas válidas de reflexão conceitual.

Seria possível pensar ainda em uma questão taxonômica dos maiores programas cult. Os fãs devotos de Star Trek recebem o nome de trekkers. Os fãs de Doctor Who são chamados de whovians, e os de Sherlock, de sherlockians. Não existe em inglês um termo para quem acompanha fielmente séries ou outros formatos. No Brasil, no entanto, ocorre o contrário. Não há o costume de um termo para denominar grupos organizados de fãs de determinada telenovela ou série, mas quem vê novelas é noveleiro, que aparece no título deste artigo. Cria-se, assim, uma nomenclatura para esses zelosos telespectadores do formato. O objeto de culto é, também e de certa forma, a telenovela em si, mesmo que existam aquelas que se destaquem nos parâmetros estéticos, de engajamento da audiência, ou de nostalgia elementos característicos de uma obra cult-.

A própria noção culto, da qual origina o termo cult, pode ser atribuída à telenovela. O caráter ritual da comunicação, segundo Carey (1992), diz respeito tanto ao hábito cotidiano quanto às suas entrelinhas simbólicas. $\mathrm{Da}$ mesma forma, a telenovela adquire características de ritual pela constituição de um hábito diário, por abarcar elementos simbólicos e mágicos atrelados à ficção (Baltazar, 2007) e por agir como reflexo da sociedade. Assim se caracteriza a comunidade em torno da telenovela e da qual os telespectadores querem fazer parte. A privacidade do ato de assistir se transforma em um ritual coletivo à medida que todos assistem ao mesmo tempo e, com muita frequência, comentam pelas redes sociais tudo aquilo que veem.

Seguindo essas premissas, a existência de programas cult com altos índices de audiência passa a ser concebida desde que a produção tenha características semelhantes às de programas já consagrados, seja no que diz respeito ao gênero da obra, às características estéticas da produção e inovação narrativa, seja no que se refere ao comportamento dos telespectadores-fãs. Assim, admite-se a existência de telenovelas cult. 


\section{Os fãs e 0 cult}

Como vimos, segundo Pearson (2010), a melhor maneira de entender o cult não é por meio da produção, mas de sua audiência. Para ela, a obra cult provoca uma atração que abarca um envolvimento físico e emocional. Assim, o fator determinante não seria o número de fãs, mas sim o engajamento deles. Por essa razão, as manifestações dos fãs são a base deste artigo no que diz respeito aos usos do termo cult nas redes, às produções citadas em questionário e, principalmente, ao engajamento capaz de constituir o elemento fundamental para a elevação de uma produção a esse status.

As raízes dos estudos de fãs são atribuídas aos estudos culturais. Da forma como conhecemos hoje, os estudos voltados à compreensão do comportamento e do conceito de "fâ" ganharam força na década de 1990, na Inglaterra, nos mesmos grupos de intelectuais que discutiam o conceito de cult. No Brasil, o debate acerca do assunto tem se aprofundado recentemente, principalmente pelo grupo Obitel, que tem se dedicado nos últimos anos à discussão do tema.

Os estudos de fãs são comumente divididos em primeira e segunda onda (Gray, Sandvoss e Harrington, 2007). A primeira onda, encabeçada por autores como Fiske (1992), Jenkins (1992) e Bacon-Smith (1992), focava nos fãs como um grupo de características semelhantes, que apresentava relação afetiva com certos programas, que complementava sua identidade. Os estudos acadêmicos sobre o comportamento desses indivíduos, apesar de terem aberto caminho para estudos posteriores, referiam-se aos fãs como "os outros", criando uma distância entre os intelectuais e seu objeto de estudo.

Essa primeira linha de estudos analisava as relações dos espectadores com os produtos culturais consumidos a partir de noções de Bourdieu (2008) como identidade, gosto e posição de classe. A obra de Fiske (1992) inspirou grande parte do arcabouço dessa primeira onda de estudos dos fãs. Ele associa o comportamento dos fãs com comunidades menosprezadas por questões de gênero, idade, classe e raça. A cultura e as atividades dos fãs seriam engajadas e intencionalmente subversivas, e os usos que os fãs e os espectadores "desempoderados" fazem da cultura popular surgiriam em 
oposição à "alta cultura” burguesa dominante. Suas análises auxiliaram na desconstrução da ideia do fã passivo, ao alegar a apropriação dos desempoderados socialmente como forma de subversão ao poder. No entanto, a própria sociologia de Bourdieu recebeu críticas por parte de alguns pesquisadores dos estudos de fãs por considerarem que suas proposições, por relacionarem fortemente o gosto à posição de classes, sempre definido socialmente, de certa forma subestimavam a liberdade individual dos consumidores.

Sandvoss (2013) defende que fãs do mesmo objeto não conferem o mesmo sentido em suas práticas, diferentemente do que julgavam alguns estudiosos da primeira onda. $\mathrm{O}$ autor acredita que as atividades e as apropriações dos fãs, dentro de uma mesma comunidade, são variadas e indicadoras de diferenças sociais e culturais, talvez mais do que os próprios objetos do fandom (atividades coletivas de fãs). A partir dessas ressalvas, Sandvoss (2013) sugere uma definição mais abrangente e descreve o fã a partir de seu "engajamento regular e emocionalmente comprometido com uma determinada narrativa ou texto" (p.9).

Fiske (1992) distingue três formas de produtividade dos fãs: semiótica, enunciativa e textual. A produtividade semiótica descreve a criação de sentido no processo da leitura e ocorre no plano intrapessoal, enquanto a enunciativa descreve as formas de interação social cultivadas por meio do consumo, por exemplo, a troca verbal entre os fãs, como as conversas e os comentários em comunidades. Por fim, a produtividade textual descreve o conteúdo gerado por fãs ao se manifestarem por meio da escrita, da edição ou da gravação de novos textos, a exemplo dos fanzines, fanfics, fan videos e afins. Assim, os fãs produtivos de modo semiótico ou enunciativo seriam aqueles que criam laços e se apropriam do objeto de admiração, enquanto os fãs produtivos renovam ou recriam textualmente esses objetos.

Apesar do eficiente ponto de partida para a análise das relações de poder nas práticas de fãs, as atividades deles como fruto de distinção de classes e da dominação burguesa ou de natureza subversiva passam a ser repensadas. A segunda onda de estudos traz, então, outra abordagem que inclui o próprio pesquisador como fã. Nos anos 2000, autores como Jenkins (2009), 
Hills (2002) e Booth (2010) dedicaram-se a análises empíricas ainda mais profundas, direcionadas às diversas práticas e aos diversos níveis do fandom. Tanto a "primeira onda" quanto a "segunda onda" desses estudos trouxeram contribuições importantes para o desenvolvimento do campo. Ambas são ainda empregadas e respeitadas, o que as diferencia são as formas de abordagem.

A segunda onda dos estudos de fãs questionou a conceituação normativa de fã, por identificar a ligação do conceito com diversos níveis de entusiasmo, em relação a muitos produtos culturais e populares em diferentes grupos sociodemográficos. Com os novos estudos, a categoria fã expandiu-se dramaticamente por serem considerados os produtos de nicho e aparelhos (celulares, games, canais do YouTube etc.).

Sandvoss (2013) reelabora as tentativas de classificação sugerindo três grupos diferentes: os fãs, os adoradores e os entusiastas. Os fãs seriam aqueles que fazem parte de um público pulverizado e acompanham de maneira intensa o texto de adoração, mas não possuem entre si vínculo hierárquico ou organizado. O segundo grupo, os adoradores, faz uso mais especializado das mídias e de seu objeto de admiração, e tendem a desenvolver laços, organizados ou não, com outros que partilham esse fandom. Por último, os entusiastas têm como cerne do fandom a atividade e a produtividade de conteúdo, mais do que a relação com o objeto midiático em si.

A segunda onda dos estudos de fãs aceita, portanto, a categoria de fã para denominar o grande grupo de espectadores fiéis, com possível laço afetivo e identificação por certo produto cultural. Segundo Sandvoss (2013), os índices de audiência e as pesquisas de mercado sobre os fãs de música ou de futebol mostram que os fãs regulares que acompanham determinado texto superam em número àqueles que comparecem a eventos presenciais, convenções ou que produzem conteúdo. Assim, fã designaria a imensa maioria do conjunto. Os adoradores existiriam em número ainda menor e os entusiastas seriam o tipo mais raro de fã, aquele que se apega ao texto e não fica satisfeito com a mera leitura ou com formas básicas de consumo. 
A diversidade de práticas desenvolvidas por fãs no Brasil é também trabalhada por Lopes et al. (2015, p. 22) por meio das tipologias compartithadores (62\%), produtores (21\%), comentadores $(15 \%)$ e curadores $(3 \%)^{2}$. Os indivíduos que realizam essas atividades formam uma pirâmide com uma espécie de gradação de engajamento, contributiva para a compreensão dos diferentes níveis de envolvimento ativo dos fãs.

Com apoio nos argumentos expostos, o fã é aqui entendido em seu significado mais amplo, como telespectador com afeto e certa dedicação pela ficção televisiva. $\mathrm{O}$ interesse por produtos e o envolvimento participativo e emocional com a produção faz parte da condição de fã, e muitas vezes faz parte menos do produto cultural do que do interesse e da admiração pessoal dos indivíduos (Fiske, 1992). O fã é então visto como sujeito ativo, produtor de sentido e, assim, contribui para a expansão do conceito de cult. Justamente por isso, as manifestações dos telespectadores são o ponto de partida desta pesquisa por constituírem um dos importantes parâmetros de avaliação de uma produção.

\section{Comunidades de fãs}

Desde o início das reflexões acadêmicas sobre fãs, atribuído em maior parte à década de 1990, os fãs eram relacionados a comunidades. Os estudos dessas comunidades surgiram acerca de ídolos musicais ou gêneros de ficção, como filmes ou programas televisivos. $\mathrm{O}$ ato de ser um fã, portanto, não seria definido apenas pelo gosto ou pela atitude individual, mas também pelo desempenho e pela participação em atividades de um grupo ou em "comunidades de interesse" (Ronsini et al., 2015). Os participantes dessas comunidades de interesse, de acordo com Ronsini et al. (2015), transitam entre diferentes contexto midiáticos (televisão, sites na internet, celulares etc.) com base nos interesses em comum; além disso, criam espaços comu-

2 A pirâmide de Lopes et al. (2015) teve como base um estudo que acompanhou no Twitter, no Facebook, no YouTube e em alguns blogs sobre novela a última semana da telenovela Passione em 2011. A tipologia é explicitada em: curadores - moderadores de comunidades e criadores de conteúdos e listas no Twitter, em blogs, no Facebook e no YouTube; comentadores - usuários que comentam criticamente as telenovelas e/ou as plataformas; produtores aqueles que interagem com outros usuários por meio de conversação, e compartilhadores — seguidores e indivíduos que divulgam conteúdos relativos à telenovela. 
nicacionais em torno de certos objetos de afeto. Esse envolvimento dos fãs em grupos ou comunidades estabelece a noção de fandom.

Para Hills (2002), o fandom é mais um ato performativo do que uma atividade concreta. $\mathrm{O}$ sujeito que participa de uma comunidade busca assumir e reivindicar a identidade de fã, pois ela oferece uma espécie de status cultural àquele grupo; com isso, ampliaria a sensação de pertencimento. Nesses grupos, ocorrem negociações culturais constantes, não apenas entre os membros da comunidade, mas também com o produtor.

Atualmente, na era da convergência, pesquisadores como Sandvoss (2013), Hills (2010) e Lopes et al. (2011) têm admitido chamar de fã aquele telespectador participativo, que cria ou produz conteúdos sobre os programas, comenta nas redes sociais e fóruns ou mesmo aquele que procura saber mais sobre o que assiste, lê sobre a produção e talvez "curta" posts a respeito no Facebook. Essa ideia pode ser justificada pelo fato de que, independentemente do nível de engajamento do telespectador nas redes sociais, ele faz parte da comunidade geral que cultua aquela produção, com gostos e interesses comuns, como membro de um fã-clube no qual nunca se cadastrou formalmente. Por isso é impraticável, ao falar sobre fãs hoje em dia, não se incluírem o fã digital e sua presença nas redes. Os estudos de fãs passam, então, a ganhar força ao analisar o digital fandom.

Para Jenkins (1992), o fandom é um espaço para manifestações prazerosas e apaixonadas dos fãs e se mostra também como uma crítica a certo tipo tradicional de consumo. São muitos os níveis de engajamento: do "curtir" ao criar. O importante é perceber a relação de sentimento e a vontade de participação do indivíduo no grupo, e incluir o telespectador que gosta de ler os comentários e os relatos dos outros telespectadores para ampliar sua visão sobre o programa. Aqueles que escrevem querem dividir experiências e, por fim, os fãs criadores de novos conteúdos (como vídeos e memes, produzidos pelos fãs, que se tornam populares na internet), querem instigar a reação dos outros participantes, por curiosidade ou mera provocação. Mesmo o que é chamado de produção do fã ou conteúdo gerado pelo usuário (CGU) não precisa ser necessariamente inovador. 
Segundo Livingstone (1990), essas criações encontram-se na intersecção entre o conteúdo midiático e suas interpretações.

A telenovela repercute no ambiente das redes sociais por meio de processos de transmidiação, oriundos tanto da produção quanto da recepção. Diversas modalidades de produção de conteúdo são exploradas, como memes, fan fictions, fan videos e outras tantas que surgem a cada dia. $\mathrm{O}$ compartilhamento das práticas de recepção e produção de sentido proporciona uma pluralidade de pontos de vista sobre a telenovela, em relação a personagens, roteiro, cenas específicas ou mesmo trilha sonora.

Esses tipos de engajamento do fã são causados pelo que Grossberg (1992) chama de sensibilidade. Esta seria um modo particular de operação, fruto do prazer e da satisfação pessoal. $O$ autor reforça também que, por ser alcançado em casa, em local e momento privado, o fã de ficção televisiva desenvolve relações de interpretação individuais e subjetivas, o que explica a importância do compartilhamento. Como veremos a seguir, os telespectadores e os fãs de telenovelas, seja no espaço virtual, seja no doméstico, participam desse universo coletivo do fandom.

\section{Pesquisa empírica: a voz dos fãs}

As pessoas falam sobre a novela de forma espontânea e com intimidade. Compartilham anseios e opiniões que podem carregar significados importantes para a compreensão de determinados conceitos no senso comum. O senso comum ao qual me refiro seria o caráter verbal e a incorporação espontânea do vocábulo cult, cujo significado foi apreendido pelos indivíduos por meio da convivência e da troca social, sem reflexão filosófica ou investigação científica. Entendido não como exterior à vida cotidiana, mas como parte dela, o senso comum (e, no caso, seu reflexo no vocabulário popular) torna-se de interesse do campo científico.

A partir disso, a pesquisa se iniciou com busca por manifestações no Twitter e análise qualitativa dos tweets encontrados. Em seguida, foi aplicado um questionário nas redes Facebook e Twitter com a intenção de encontrar as telenovelas consideradas cult pelos telespectadores. A terceira etapa 
consistiu na realização de dois grupos focais com o objetivo de avaliar os possíveis motivos da escolha das produções mais citadas. Sempre em vias de conceder a voz aos fãs, segue-se uma análise de Avenida Brasil ${ }^{3}$, devido à atenção que essa produção recebeu nos grupos focais e ao destaque recebido pelo engajamento da audiência, uma das principais características do cult apontada pelos estudiosos do assunto.

\section{Usos do termo no Twitter}

O Twitter foi escolhido por ter como característica frases curtas que manifestam opiniões em poucas palavras. Assim, é possível uma visão da expressão por pessoas que conversam sem problematização profunda dos conceitos, mas atribuem sentido a eles. A hipótese era de que os resultados mostrassem a palavra cult relacionados a algo "para poucos", distante do popular — próxima da definição de Hills (2010) sobre o que o cult não é-. De fato, isso ocorreu, mas um surpreendente número de comentários revelavam tom pejorativo, como se criticassem essa distinção.

Em busca no Twitter, pela ferramenta Topsy, no dia 6 de agosto de 2015, a palavra cult nos últimos 30 dias apareceu em 163.606 tweets de língua portuguesa. A média de mais de 5 mil tweets por dia pode ser considerada suficiente para mostrar que o uso da palavra existe em abundância. Após os exemplos de uso isolado dessa palavra, foi feita busca com a expressão novela cult, sem aspas, para que fossem encontradas frases que fizessem uso das duas palavras, mas não necessariamente unidas. $\mathrm{O}$ número encontrado foi significativamente mais baixo do que da palavra cult isolada. Nos últimos 30 dias, apenas 20 tweets fizeram alguma associação entre novela e cult. Nos últimos 6 meses, esse número soma 97 resultados.

Esses resultados, que combinam as palavras novela e cult, foram analisados qualitativamente, com base em seu conteúdo e em relação ao tipo

3 Avenida Brasil foi uma telenovela produzida pelo canal de televisão Globo, exibida de março a outubro de 2012 no horário das $21 \mathrm{~h}$. Foi escrita por João Emanuel Carneiro e produzida por Ricardo Waddington, Amora Mautner e José Luiz Villamarim. A trama contou a história de vingança da personagem Rita, que, após a morte de seu pai quando criança, foi abandonada num lixão por sua madrasta Caminha. Ao crescer, a jovem Rita assume o nome Nina e é contratada como cozinheira na mansão de Carminha, agora casada com um rico ex-jogador de futebol. 
de ligação feita entre as duas palavras. Tais tweets puderam ser classificados em três categorias: 1) oposição, quando a novela foi colocada em oposição a algo cult; 2) crítica à oposição, quando a frase apontava crítica ou ironia à existente oposição entre os termos; 3) combinação, quando as noções de novela e cult são combinadas, colocadas juntas como possíveis, e 4) outros, sobre assuntos adversos.

\section{Gráfico 1. Classificação dos tweets (novela-cult)}

\begin{tabular}{|l|r|r|}
\hline \multicolumn{1}{|c|}{ Tweets } & N. $^{\mathbf{0}}$ & \multicolumn{1}{c|}{$\mathbf{~ \% ~}$} \\
\hline Oposição & 15 & 15 \\
\hline Crítica & 24 & 25 \\
\hline Combinação & 32 & 33 \\
\hline Outros & 26 & 27 \\
\hline Total & $\mathbf{9 7}$ & $\mathbf{1 0 0}$ \\
\hline
\end{tabular}

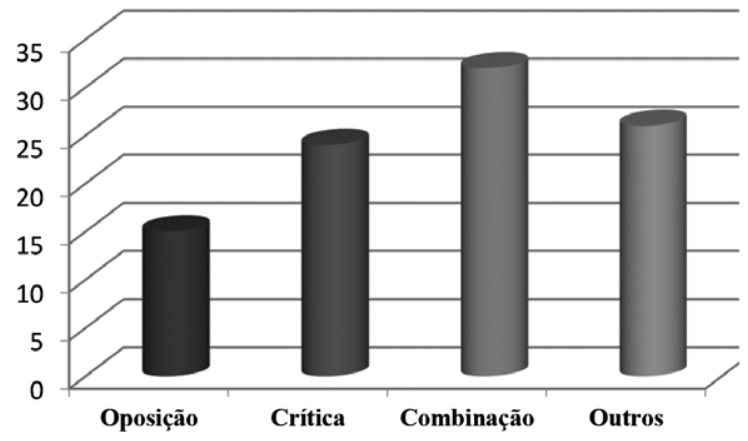

Fonte: Greco, 2016.

Conforme ilustra o gráfico, nota-se que, desses 97 tweets, a maioria (33 \%) se refria a uma combinação entre a novela e a noção de cult, enquanto a minoria ( $15 \%$ ) propagava a oposição dos termos, como em "[m]inha vida às vezes parece uma novela mexicana e outras vezes parece um filme cult argentino." O tweet destacado expressa as noções de cult e de novela como coisas opostas. Há um entendimento comum de que cult é ler, ir à ópera ou ver filmes estrangeiros ou independentes (não hollywoodianos). Outro exemplo foi a frase "[p] areço hipster cult indie conceitual mas parei de fazer minhas artes pra assistir a novela”, a qual revela uma concepção de distância entre as atividades (ser cult e ver novela). Por outro lado, admite que assiste à novela, de modo a encurtar essa distância.

Outros 24 tweets criticavam ou ironizavam essa oposição. Cientes de que a oposição entre a ideia de cult e a telenovela existe, posicionam-se con- 
tra isso, questionando os motivos dessa distinção ou demonstrando não entender seu sentido. São exemplos ${ }^{4}$ :

"Desculpa gente se eu to vendo novela e nao to sendo pseudo cult lendo livro dificil e fingindo que entendo."

"Se você discutir o final de uma novela da Globo é cafona. Agora, se for 0 final de Mad Men... cult cult. Tá bom. Hahaha"

"Pessoal do Twitter ama pagar de 'sou muito cult pra assistir Globo', acontece qualquer coisa na novela e 5 minutos depois já está nos trends."

"Mimimi eu não gosto de novela sou cult só assisto série mimimi Miga deixa eu te falar é praticamente a mesma coisa."

Esses comentários são claros em evidenciar a ridicularização do tipo pejorativo cult, apreciador de Mad Men ou de "livro difícil". Referem-se a pessoas que não são adeptas de novelas ou programas populares, que seriam seguidores apenas de séries ou filmes cult, no sentido "lado B". Esses exemplos acompanham a crítica à oposição entre os termos, porém com abordagem irônica e debochada. Os autores desses comentários parecem achar o desprezo pelas novelas ante a exaltação de produtos não populares algo descabido e motivo de chacota.

A maioria dos tweets, no entanto, conseguiu admitir ou relacionar a ideia de cult com alguma telenovela. Em contraposição aos exemplos vistos até o momento, 32 postagens associaram a novela a algum possível elemento cult ou, simplesmente, expressaram a opinião de que a cena ou a novela são, em sua opinião, cult. Esses comentários eram feitos de forma direta ("Essa novela é muito cult, gente."), por associação com um lado hipster ("É uma novela meio hipster/cult."), por associação com algo não popular ("Mas, gentem, que novela das 6 é essa que toca Nina Simone, Louis Armstrong e Bob Dylan? que cult.") ou por seu caráter trash ("Essa abertura da novela Maria Esperança é tão trash que é um cult."). Avenida Brasil também apareceu nos comentários. "Avenida Brasil nos TT’s. Perfeição

4 A escrita dos tweets foi mantida conforme original. As palavras telenovela, novela e cult foram destacadas pela autora para apontar as palavras-chave em questão. 
de novela, a última do horário nobre $\mathrm{q}$ foi esplêndida e um fenômeno. $<3$ Virou cult como \#ValeTudo."

Percebe-se, nesses exemplos, a combinação dos termos sem carga aparente de preconceito ou ironia. Independentemente da abordagem, o ponto principal é a aceitação de que uma telenovela pode ser cult ou apresentar uma cena desse tipo, sem causar grande estranhamento.

\section{Questionário e grupos focais}

A segunda etapa da pesquisa empírica foi a aplicação de questionário que continha uma só pergunta nas redes sociais (alguns pesquisadores diriam formulário por ter sido respondido pelo próprio participante). Questionário ou formulário, ambos consistem em técnica de pesquisa que permite maior alcance de pessoas e se destaca pela economia de tempo. É importante, no entanto, que as questões a serem respondidas sejam do universo do respondente, pois a imposição de uma problemática que não é a do usuário pode estimular respostas reativas (Thiollent, 1986). Ciente disso, ao desenvolver o questionário, o objetivo tornou-se descobrir quais telenovelas são consideradas cult.

A intenção de um questionário com apenas uma pergunta foi um experimento metodológico, com vistas a arrecadar maior número de respostas. Além disso, o objetivo dessa etapa era fazer uma pré-seleção de títulos a serem analisados ao longo da pesquisa. As principais questões-chave buscadas pela pergunta eram: os telespectadores admitem a existência de uma telenovela cult? Se sim, quais seriam essas telenovelas? Haveria concordância entre os títulos escolhidos? Essas três perguntas podem ser esclarecidas a partir de apenas uma: qual telenovela, de todos os tempos, você considera cult? (pode ser mais de uma).

A divulgação da pergunta-questionário foi feita a partir do perfil da pesquisadora no Facebook e no Twitter, e recebeu compartilhamentos de pessoas de tal círculo. Com isso, é preciso ter em mente que a amostra da qual falamos é composta por indivíduos com um ou no máximo três graus de separação entre si. O contraponto a esse possível viés é dado pelo fato de que o universo dos fãs que utilizam o termo cult é majorita- 
riamente jovem, e as redes sociais em questão contam com vasta presença de usuários com grau de instrução mais elevado (universitários ou jovens profissionais), compatíveis com o perfil da pesquisadora.

O questionário recebeu 346 respostas em um mês ${ }^{5}$, que citaram 78 títulos de telenovelas. Por um olhar quantitativo, o alto número de produções mencionadas revela a efervescência da memória televisiva, individual e coletiva. Ainda pelo viés numérico, outro ponto importante para iniciar a análise é o número de respostas que rejeitam a pergunta sugerida. Entre as pessoas que responderam, 24 consideram "nenhuma" telenovela cult. $\mathrm{O}$ dado é significativo, mas não dominante. Apenas $7 \%$ das pessoas que responderam não acreditam que uma telenovela possa ser cult, enquanto $93 \%$ dos respondentes apontaram pelo menos um título. Eis o primeiro dado, em resposta à primeira questão-chave: os telespectadores admitem a existência de uma telenovela cult? Concluiu-se que, em princípio, sim. Parte-se então para as outras questões: quais seriam elas e se há concordância entre os telespectadores. A Tabela 1 revela as cinco telenovelas mais citadas.

Tabela 1. Telenovelas mais citadas no questionário
\begin{tabular}{|c|c|c|c|}
\hline & Título & Ano & Menções \\
\hline 1 & Roque Santeiro & 1985 & 60 \\
\hline 2 & Que Rei Sou Eu? & 1989 & 31 \\
\hline 3 & Avenida Brasil & 2012 & 27 \\
\hline 4 & Vale Tudo & $1988-1989$ & 27 \\
\hline 5 & Vamp & $1991-1992$ & 23 \\
\hline
\end{tabular}

Fonte: Greco, 2016.

A tabela mostra a resposta à pergunta sobre quais seriam os títulos considerados cult e mostra que, apesar do grande número de títulos mencionados, existe sim concordância entre muitas pessoas. Roque Santeiro foi a telenovela considerada cult pelo maior número de respondentes, com quase o dobro de menções em relação à segunda, Que Rei Sou Eu?. Avenida Brasil e Vale Tudo receberam o mesmo número de respostas ${ }^{6}$.

5 De 28 de abril a 28 de maio de 2015.

6 Nesse caso, foram organizadas por ordem alfabética. 
Após o questionário que indicou as novelas considerada cult pelos telespectadores, foram realizados dois grupos focais exploratórios que visavam à confirmação de hipóteses sobre os motivos dessas menções e à avaliação da teoria (Gondim, 2003). O primeiro grupo reuniu oito participantes em Belo Horizonte, e o segundo grupo seis participantes em São Paulo, convidados por meio de redes sociais. As características pretendidas eram as de jovens-adultos, de 25 a 40 anos, com alto grau de escolaridade (ao menos superior em curso), compatíveis com o suposto perfil dos respondentes do questionário e com o nicho de público que utiliza o termo cult.

Partindo então do ponto de vista qualitativo, o primeiro dado a ser notado é a questão temporal, que pode ter provocado a lembrança desses títulos. A única telenovela recente é Avenida Brasil, exibida três anos antes da realização da pesquisa. As outras são produções de, no mínimo, duas décadas atrás, porém, conforme lembrado pelos participantes, todas reprisadas no canal $\mathrm{Viva}^{7}$ nos cinco anos anteriores à pesquisa. $\mathrm{O}$ fato chamou a atenção dos participantes dos grupos focais, que tocaram no caráter nostálgico da maioria desses títulos. Isso indica que a memória televisiva dos telespectadores pode até ter raízes antigas, mas foi possivelmente irrigada pelas reprises.

De acordo com os participantes dos grupos focais, Vale Tudo e Roque Santeiro evocam, ainda, valor nostálgico por trazerem personagens emblemáticos, como Sinhozinho Malta e Odete Roitman, além de temáticas com crítica política e social. Isso significa que, mesmo sem problematizarem o conceito, os telespectadores também tendem a associar o cult a produções com elementos nostálgicos, inovações estéticas ou conteúdo engajado, como sugere a teoria.

Os grupos apontaram, ainda, que algumas dessas telenovelas se destacam por apresentar abordagem estética diferente do padrão ao qual o

7 O canal Viva, pertencente à Globosat (das corporações Globo), foi criado em 2010 e tem como proposta a memória da emissora. Ocupam sua grade reprises de ficção televisiva e programas que recuperam a memória da TV Globo por meio de arquivos ou entrevistas. 
público está acostumado, como Que Rei Sou Eu? e Vamp. A fotografia, os figurinos ou os elementos fantasiosos dão um tom diferenciado à trama, alheio à usual proximidade com a realidade. No caso de Vamp, foi ressaltado pelos participantes também o gênero vampiresco ou trash, reforçado por Abbott (2010) como sendo um dos principais gêneros dentro do espectro do $\mathrm{cult}^{8}$.

Entre essas produções, no entanto, Avenida Brasil foi considerada discrepante das demais. Os grupos consideraram que, por ser muito recente e ter sido muito popular, não se encaixavam nos mesmos critérios que as outras telenovelas consideradas cult. Os participantes destacam, porém, que ela foi marcante; lembram-se de onde estavam no dia do último capítulo; comentam as ruas vazias e os bares que exibiram o desfecho e mencionam o "clima de final de Copa do Mundo" que se instaurou no país. Associaram, então, a razão de tantas menções às atividades dos fãs que dominaram as redes sociais - apontamento em consonância com o aporte teórico apresentado até agora-.

Para além das práticas de recepção, no que diz respeito à narrativa e à produção, uma participante do grupo de São Paulo discordou da colocação de Avenida Brasil por sentir falta de personagens icônicos. Ao que outra contrapôs "defendendo" (em suas próprias palavras) Avenida Brasil por seu conteúdo, pela trama forte e por seu impacto na audiência, além da estética da produção, da iluminação e da ambientação noir. A participante em questão se mostrava entusiasmada e disse ainda acreditar que Carminha representa um ícone da telenovela nacional. Com isso, percebe-se também que o sentimento de "defesa" da participante se assemelha ao que Peary (1981) relata sobre os fãs de filmes cult, que alegam que "seus filmes favoritos são os mais intrigantes, incomuns, ultrajantes, misteriosos, absurdos,

8 Produções com estética trash, derivada da palavra lixo, em inglês, são um consideradas um gênero comum entre as produções ditas cult. Enquanto o trash está mais relacionado às características de produção e do filme em si, o cult estaria mais ligado à recepção dessas produções. Assim, os filmes trash possuem características em comum e podem se tornar cult, enquanto os filmes cult não necessariamente apresentam estética trash. Claramente, os dois conceitos se sobrepõem de diversas maneiras, e muitos filmes desenvolveram seguidores cult justamente por causa de suas qualidades trash. Essas produções são consideradas, inclusive, precurssoras do cult, mas não limitam o conceito. 
desafiadores, divertidos, eróticos, exóticos, e-ou melhores filmes de todos os tempos." (p. xiii).

A partir dos elementos apontados pelos teóricos do cult e com base nos resultados do questionário, das conversas com os grupos focais, confirmou-se que aquelas produções que os brasileiros consideram cult contêm, ao menos, um entre os elementos apontados por Pearson (2004) (apelo nostálgico, conteúdo crítico ou estética inovadora, engajamento de fãs). As produções mais mencionadas puderam ser classificadas em cult nostálgico, cult estético e cult contemporâneo (Greco, 2016). A primeira categoria diz respeito às telenovelas que marcaram a teledramaturgia e são constantemente lembradas por personagens marcantes, bordões ou mesmo pela trama (Roque Santeiro e Vale Tudo); a segunda categoria relaciona-se ao caráter estético, da alçada da produção e da imagem (Que Rei Sou Eu? e Vamp); por fim, o cult contemporâneo remete àquela produção cuja audiência é de tal forma expressiva e/ou engajada que ela se torna um cult ainda no momento em que é exibida. Nessa classificação, encontra-se Avenida Brasil, foco deste artigo, que visa pensar o cult em relação às práticas de fãs.

Por ter sido considerada discrepante e por ter sido a única telenovela entre as mais citadas cuja alusão ao cult foi relacionada com o engajamento da audiência, neste artigo Avenida Brasil recebe análise particular. Nela, as manifestações de fãs na época de sua exibição surpreenderam aos produtores, aos críticos e aos brasileiros em geral, pois há tempos não se via tamanha vivacidade da audiência. Apesar de apresentar elementos estéticos de certa forma inovadores e referências intertextuais, acredita-se que Avenida Brasil foi considerada cult pelos telespectadores, principalmente, pelo engajamento dos fãs nas redes sociais.

\section{Avenida Brasil: um cult contemporâneo}

A telenovela da Globo, exibida de março a outubro de 2012, foi escrita por João Emanuel Carneiro e produzida por Ricardo Waddington, Amora Mautner e José Luiz Villamarim. Sucesso estrondoso de crítica e público, a produção foi apontada como destaque do ano de 2012 no Anuário Obi- 
tel 2013 (Lopes et al., 2013). Não só do ano, Avenida Brasil foi destaque na história da teledramaturgia brasileira.

Com temática clássica de vingança, Avenida Brasil apresentou personagens complexos, imbuídos de bem e mal, distante da clássica dualidade entre mocinho e bandido muitas vezes atribuída ao melodrama. Em meio à trama de suspense e vingança, em tom noir, fez com que os telespectadores criassem profunda identificação e, por consequência, afeto. Além disso, trouxe elementos estéticos incomuns e foi a primeira telenovela do horário das $21 \mathrm{~h}$ (o mais nobre da Globo) a apresentar gravação em 24 quadros, com imagem de película de cinema. A ambientação era escura, os personagens multifacetados e os diálogos bem trabalhados. O perfil dos personagens se distanciou do costume de retratar os ricos na alta sociedade. $O$ protagonismo ficou com a classe $C$, que enriqueceu no subúrbio e lá permaneceu, no fictício bairro do Divino, no qual os personagens moravam desde a infância. Apesar da mansão e do costume de tomar champanhe, os personagens eram simples, falavam alto, não tinham noção de etiqueta, eram trabalhadores e solidários. Estavam presentes o futebol, a cerveja, o samba e o carnaval. As consequências foram identificação e comoção massivas que puderam ser vistas e acompanhadas on-line.

A trama apresentava poucos personagens, o que colaborou para aumentar o envolvimento emocional com cada um. Os conflitos eram resolvidos com rapidez, a cada semana um degrau da vingança era cumprido, o que evitava a famosa "barriga" das novelas, momento de possível perda da fidelidade dos telespectadores. Algumas cenas aproximavam-se de gêneros de suspense e terror ou faziam referências a outras obras clássicas. Em uma das cenas mais comentadas, a vilã Carminha enterra viva a mocinha vingativa Rita (que muda seu nome para Nina). A aspirante à mocinha, no entanto, consegue escapar e anda pela estrada cambaleante, em estilo zumbi. No Twitter, os internautas comentaram a maldade da atitude de Carminha e compararam a história a filmes como Kill Bill, Jogos Mortais e Jogos Vorazes, e ao seriado The Walking Dead.

9 O termo popular barriga da novela refere-se aos capítulos em que não ocorrem conflitos ou resolução deles, o que dá a impressão de que a trama avançou pouco ou quase nada no período. 


\section{Figura 1. Cena de Avenida Brasil: Nina após ser enterrada viva}

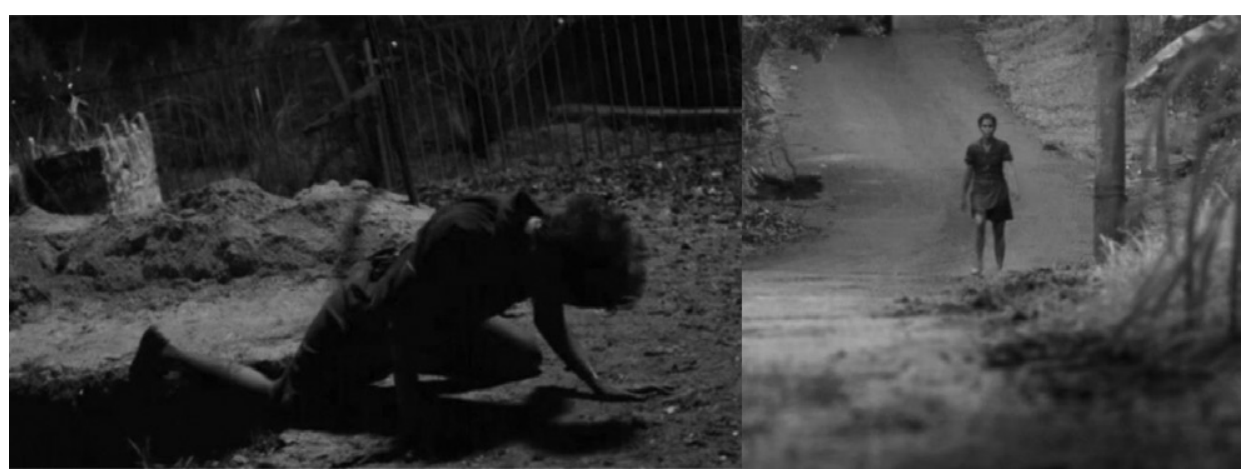

Fonte: Capítulo 100, disponibilizado na plataforma Gshow, da Rede Globo.

Essa cena talvez seja a que mais recebeu alusões ao cinema, entre as várias percebidas no folhetim. Foi um dos momentos que levou ao hashtag \# oioioi (referente ao refrão da música) aos trending topics do Twitter. As pessoas compartilhavam opiniões sobre a maldade, a intensidade ou a força da cena. A cena foi inclusive recriada em homenagem à novela dois anos depois, em 2014, no Vídeo Show, programa de informações e memória da TV com ênfase em ficção televisiva.

O fato remete à afirmação de Eco (1985) sobre ser comum em filmes cult, apesar de não obrigatório, o uso de referências a outras obras, como menções a cenas, diálogos, situações ou elementos presentes em produções anteriores. Além da cena acima referida, outro exemplo mais cômico se deu quando a família Tufão decide viajar para a praia em uma kombi azul, lembrando a icônica van amarela de A Pequena Miss Sunshine (2006). Não bastasse a referência ao automóvel, a kombi azul da novela também precisou ser empurrada. Outra semelhança era a filha de Tufão, Ágata (Ana Karolina), a criança gordinha que gostava de dançar, como a personagem do filme, Olive Hoove (Abigail Breslin). Como alerta Patrícia Villalba (2012), o uso desse tipo de referência não deve ser visto como mera imitação. Basta lembrar que os mesmos filmes citados são recheados de referências cinematográficas.

Afora os filmes, Avenida Brasil apresentou na narrativa também inúmeras referências literárias que chamaram a atenção de jornalistas e do pú- 
blico mais atento. Perto de virar o jogo e se vingar da ex-madrasta Carminha, a empregada Nina presenteia o patrão, Tufão, com o livro $O$ Primo Basilio. No livro de Eça de Queiroz, a empregada Juliana é a vilã, uma jovem ressentida e invejosa, que chantageia a patroa. Na telenovela, o marido Tufão não percebe a semelhança da literatura com sua vida, mas o público alerta identifica a provocação, já que nos capítulos seguintes a cozinheira Nina incorpora uma Juliana de 1878 em versão moderna. $\mathrm{O}$ mesmo feito se repete com outros clássicos da literatura nacional. Durante os sete meses da novela, Tufão leu dez livros por indicação de Nina. Entre eles constam O Idiota, de Dostoievski, Dom Casmurro, de Machado de Assis, Madame Bovary, de Gustave Flaubert e A Metamorfose, de Franz Kafka.

Todas essas ocorrências movimentaram as redes sociais. Foi provavelmente durante Avenida Brasil que se consolidou o hábito de assistir a telenovelas concomitante a conversas no Facebook e no Twitter. A novela foi o tema mais comentado nessas redes em 2012. No Twitter, suscitou cerca de 200 trending topics durante a exibição da novela, média de 15 por $\operatorname{dia}^{10}$, e atingiu a marca de 3.031 tweets por minuto durante a exibição do último capítulo (Superinteressante, 2012). Em relação aos CGU, muitos foram os memes com montagem de fotos a caricaturas, vídeos e brincadeiras com os bordões dos personagens, especialmente com o fundo congelado da abertura e com os bordões "Me Serve, Vadia", "É tudo culpa da Rita" e "Oi, oi, oi”.

Convém ainda relembrar o dia da exibição do último capítulo, cujas ruas vazias sinalizavam a ocorrência de um "evento midiático" (Couldry e Hepp, 2010). Na véspera do "evento", a mídia noticiava a ansiedade nacional, com base em dois fatos curiosos: o cancelamento da participação da presidente Dilma Rousseff em um comício do então candidato a prefeito de São Paulo, por receio de que não houvesse público (já que todos estariam assistindo ao último capítulo da novela) e a preocupação do Operador Nacional de Energia Elétrica do País, que reforçou o oferecimento de energia por prever o aumento de consumo durante a exibição do folhetim

10 Afirmação feita por Luiz Erlanger, então diretor da Central Globo de Comunicação, durante o VII Seminário Obitel em 2012. 
e após ela —o medo era que ocorresse um apagão devido ao alto consumo de energia elétrica (o que não aconteceu)—.

O fervor e a quantidade de comentários, memes e vídeos têm, obviamente, relação com o engajamento dos telespectadores, mas não se pode ignorar as estratégias da produção para incentivar as manifestações da audiência. A Globo conta com um departamento e estratégias para incentivar, unir, controlar e mensurar esse engajamento. No entanto, isso não significa que a produção tenha sido a maior responsável pelo engajamento nas redes. Os principais responsáveis pelo fenômeno fora das telas foram os fãs, espontâneos e com grande entusiasmo.

Esse afeto escancarado, o saudosismo exposto, o engajamento do público e a admiração da crítica manifestam claramente a diferença entre a audiência e a repercussão de Avenida Brasil em relação a outras telenovelas brasileiras recentes. $\mathrm{O}$ culto foi intenso, participativo e fervoroso. $\mathrm{O}$ ato de assistir à TV e comentar nas redes sociais foi acentuado, com características de um verdadeiro culto. Sem dúvida, colaborou para uma unidade simbólica nacional e se tornou um ícone da TV brasileira; em resumo, um cult.

\section{Considerações finais}

As páginas anteriores expuseram um quadro teórico sobre a TV cult, com consulta empírica e análise de Avenida Brasil como exemplo de uma produção que obteve destaque pelo engajamento dos fãs. $O$ principal desafio (e resultado) foi romper com a ausência de estudos brasileiros sobre o conceito e adaptar a teoria internacional ao contexto da telenovela brasileira. A aparente rigidez inicial em definições como o cult avesso ao mainstream foram desconstruídas a partir de novos autores que aceitam o cult popular e da interpretação de fã com seus diversos níveis de engajamento.

$\mathrm{O}$ artigo parte da premissa de que é função da ciência investigar e analisar os sentidos criados e reproduzidos no senso comum. A voz da audiência como fonte de dados relevantes para pesquisa é também forma de valorização da opinião do público e do entendimento do telespectador 
como crítico e construtor de sentidos. A busca de comentários, a aplicação do questionário e a realização dos grupos focais permitiram a identificação e a compreensão de usos diversos do conceito. Foi possível reconhecer a classificação de telenovelas como cult por características presentes na produção, como figurinos ou elementos fantásticos ou por sua aura nostálgica, derivada do afeto dos telespectadores. Notou-se também que o engajamento de fãs e o afeto pela narrativa, com manifestação nas redes sociais e fora delas, pode criar um cult imediato, enquanto é exibida.

Retomadas as orientações propostas por Pearson (2010) e Eco (1985), notam-se aproximações entre o conceito de cult e o caso Avenida Brasil. A obra angariou telespectadores engajados e envolvidos, e a ligação com os personagens fez criar um universo completo, no qual os fãs desejavam habitar. Até mesmo as referências a outras obras literárias ou audiovisuais, o quarto elemento cult citado por Eco (1985), estavam presentes. Mas foi o engajamento dos fãs o principal aspecto que levou a telenovela a ser considerada cult. Vale reforçar que esta pesquisa não tem intenção chancelar qual produção é ou não cult; apenas busca elencar percepções advindas de dados empíricos.

Essas reflexões buscam contribuir para o avanço nos estudos de fãs e na consolidação do objeto junto a outros campos de conhecimento. As manifestações dos fãs nas redes sociais contrapõem as críticas negativas à "perda de tempo", aclamada por alguns pensadores, e concedem uma função à análise do que consideram "supérfluo". Pensar no valor produzido e gerado pelos fãs é importante para desconstruir o preconceito ainda existente contra a televisão e seus produtos. No campo dos estudos de ficção televisiva, o movimento de se mapear e entender esses novos conceitos ou expressões é também uma forma de estimar a ficção televisiva nacional. Almejar a colocação da telenovela como cult é um meio de posicioná-la como arte, passível de valor estético e de culto, motivação constante da pesquisa de televisão no Brasil.

Além dessa satisfação, ficam os desejos, que se traduzem em sugestões, de futuras análises aprofundadas, como um diagnóstico minucioso também sobre o caráter nostálgico e estético das telenovelas brasileiras; 
melhor compreensão dos diversos níveis de engajamento e relação entre os fãs de ficção televisiva, e ampliação das análises para descobertas de outras produções brasileiras que podem ser chamadas de cult.

\section{Referências}

Abbott, S. (2010). The Cult TV Book: from Start Trek to Dexter, new approaches to TV outside the box. Berkeley, CA: Soft Skull Press.

Bacon-Smith, C. (1992). Enterprising Women: Television Fandom and the Creation of Popular Myth. Filadélfia: University of Penssylvania Press.

Baltazar, A. (2007). Mito, Mídia e Magia. O Encantamento da Televisão na Cultura Brasileira Contemporânea. Idéias. Revista do Instituto de Filosofia e Ciências Humanas, ano 14 v. 1-2,161-199.

Booth, P. (2010). Digital Fandom: new media studies. Nova York: Peter Lang.

Bourdieu, P. (2008). A Distinção: crítica social do julgamento. $1^{a}$ reimp. São Paulo: Edusp; Porto Alegre: Zouk.

Carey, J. (1992). Communication as Culture: Essays on Media and Society. Londres: Routledge.

Couldry, N. e Hepp, A. (2010). Introduction: Media Events in Globalized Media Cultures. Em Couldry, N., Hepp, A. e Krotz, F. (eds.), Media Events in a Global Age (p. 1-19). Londres: Routledge.

Depexe, S. (2015). Circulação e consumo da telenovela Salve Jorge: o caso de Maria Vanúbia no Twitter. Revista Novos Olhares, 4(1), 258-271.

Eco, U. (1985). “Casablanca”: Cult Movies and Intertextual Collage. SubStance, $14(2)$, n. 47, 3-12. 
Fiske, J. (1992). The Cultural Economy of Fandom. Em Lewis, L. A. (ed.), The Adoring Audience: Fan Culture and Popular Media (p. 30-49). Londres: Routledge.

Gondim, S. M. G. (2003). Grupos Focais como Técnica de Investigação Qualitativa: desafios metodológicos. Revista Paidéia, 12(24), 149-161.

Grant, B. K. (2000). Second Thoughts on Double Features: Revisiting the Cult Film. Em Mendik, X. e Harper, G. (eds.), Unruly Pleasures: The Cult Film and Its Critics (p. 15-27). Guildford: FAB Press.

Gray, J., Sandvoss, C. e Harrington, C. L. (2007). Fandom: Identities and Communities in a Mediated World. Nova York University Press.

Greco, C. (2016). TV Cult no Brasil: memória e culto às ficções televisivas em tempos de mídias digitais (Tese de doutorado). Escola de Comunicações e Artes da Universidade de São Paulo, São Paulo, Brasil.

Grossberg. L. (1992). Is There a Fan in the House?: the Affective Sensibility of Fandom. Em Lewis, Lisa A. (ed.), The Adoring Audience: fan culture and popular media. (p. 50-65). Londres: Routledge.

Gwenllian-Jones, S. e Pearson, R. (2004). Observations on Cult Television. Em Gwenllian-Jones, S. e Pearson, R. (eds.), Cult Television (p. 7-18). Minneapolis: University of Minnesota Press.

Hills, M. (2015). O Fandom como Objeto e os Objetos do Fandom. Entrevista a Clarice Greco. MATRIZes, 9(1), 147-163.

Hills, M. (2010). Mainstream Cult. Em Abbot, S. (ed.), The Cult TV Book: from Star Trek to Dexter, new approaches to TV outside the box ( $\mathrm{p}$. 67-73). Nova York: Soft Skull Press.

Hills, M. (2002). Fan Culture. Londres: Routledge. 
Jancovich, M. e Hunt, N. (2004). The Mainstream, Distinction and Cult TV.Em Pearson, R. e Gwenllian-Jones, S. (eds.), Cult Television (p. 27-44). Minneapolis: University of Minnesota Press.

Jenkins, H. (2009). Cultura da Convergência. São Paulo: Aleph.

Jenkins, H. (1992). Textual Poachers - Television Fans and Participatory Culture. Nova York: Routledge.

Lavery, D. (ed.). (2010). The Essential Cult TV Reader. Kentucky: The University Press of Kentucky.

Le Guern, P. (2004). Toward a Constructivist Approach to Media Cults. Em Pearson, R. e Gwenllian-Jones, S. (eds.), Cult Television (p. 3-17). Londres: University of Minnesota Press.

Livingstone, S. (1990). Making Sense of Television: the Psychology of Audience Interpretation. Oxford: Pergamon Press.

Lopes, M. V. I. et al. (2013). Brasil: a telenovela como fenômeno midiático. Em Lopes, M. I. V. de e Gómez, G. O. (orgs.), Memória Social e Ficção Televisiva em Países Ibero-americanos. Anuário Obitel 2013 (p. 129-168). Porto Alegre: Sulina.

Lopes, M. V. I. et al. (2015). A autoconstrução do fã: performance e estratégias de fãs de telenovela na internet. Em Lopes, M. I. V. (org.), Por uma Teoria de Fãs da Ficção Televisiva Brasileira (p. 17-64). Porto Alegre: Sulina.

Pearson, R. (2010). Observations on Cult Television. Em Abbot, S. (ed.), The Cult TV book: from Star Trek to Dexter, new approaches to $T V$ outside the box (p. ix-xx). Nova York: Soft Skull Press.

Pearson, R. (2007). Bachies, Bardies, Trekkies, and Sherlockians. Em Gray, J. A., Sandvoss, C. e Harrington, C. L. (eds.), Fandom: Identities 
and Communities in a Mediated World (98-109). Nova York: New York University Press.

Peary, D. (1981). Cult Films: the Classics, the Sleepers, the Weird, and the Wonderful. New York: Dell Publishing.

Ronsini, V., Brignol, L., Storch, L., Marques, C., Foletto, L. R. e Corrêa, L. B. (2015). Ativismo de fãs e disputas de sentidos de gênero nas interações da audiência de Em Família nas redes sociais. Em Lopes, M. I. V. (org.), Por uma Teoria de Fãs da Ficção Televisiva Brasileira (p. 197-238). Porto Alegre: Sulina.

Sandvoss, C. (2013). Quando Estrutura e Agência se Encontram: os fãs e o poder. Ciberlegenda, 28(1), 8-41.

Superinteressante. (14 dez. 2012). O melhor do ano: os assuntos mais comentados no Facebook. Recuperado em http://super.abril.com.br/ blogs/superlistas/o-melhor-do-ano-os-assuntos-mais-comentados-no-facebook/ [Citado em $1^{\circ}$ fev. 2016].

Thiollent, M. J. M. (1986). Crítica Metodológica, Investigação Social e Enquete Operária. $5^{\text {a }}$ ed. São Paulo: Editora Polis.

Villalba, P. (23 jul. 2012). “Avenida Brasil” recorre a Eça de Queiroz. Veja on-line. Recuperado em http://veja.abril.com.br/blog/quantodrama/folhetinescas/avenida-brasil-recorre-a-eca-de-queiroz/ [Citado em 30 set. 2015].

Williams, R. (2013). Torchwood Declassified - Investigating Mainstream. Cult Television. Londres: I.B. Tauris. 